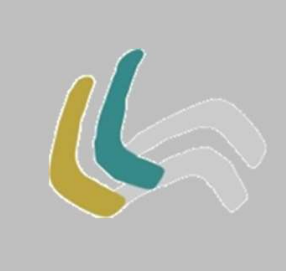

\title{
O HOMO SACER CONTEMPORÂNEO E A NECROPOLÍTICA NO CONTO “ESPIRAL" DE GEOVANI MARTINS
}

\section{CONTEMPORARY HOMO SACER AND NECROPOLITICS IN THE SHORT STORY “ESPIRAL” BY GEOVANI MARTINS}

\author{
Jeniffer Geraldine Pinho Santos 1 \\ Universidade do Estado da Bahia
}

Resumo: A proposta deste artigo é, a partir do conto "Espiral", presente no livro O sol na cabeça (2018), do escritor brasileiro Geovani Martins, apresentar os conceitos: Homo Sacer, trabalhado pelo filósofo italiano Giorgio Agamben (2007), e Necropolítica, a política da morte, elaborado pelo filósofo camaronês Achille Mbembe (2018). As discussões levantadas a partir dos conceitos citados também serão amparadas em Sueli Carneiro (2011) e Vladimir Safatle (2018). Com esta articulação interessa observar como a representação da desigualdade e da violência na literatura brasileira contemporânea contribui para debater questões sociais e políticas da contemporaneidade.

Palavras-Chave: Homo Sacer; Biopolítica; Necropolítica; Literatura Contemporânea.

1 Endereço eletrônico: jeniffergps@gmail.com. 
Abstract: The proposal of this article is, based on the short story "Espiral", present in the book O sol na cabeça (2018), by the Brazilian writer Geovani Martins, to present the concepts: Homo Sacer, by the Italian philosopher Giorgio Agamben (2007), and Necropolitics, the politics of death, by the Cameroonian philosopher Achille Mbembe (2018). The discussions raised from the cited concepts will also be supported by Sueli Carneiro (2011) and Vladimir Safatle (2018). With this articulation, it is of interest to observe how the representation of inequality and violence in contemporary Brazilian literature contributes to debate social and political issues of contemporaneity.

Keywords: Homo Sacer; Biopolitics; Necropolitics; Contemporary Literature.

Em março de 2018, parte da mídia especializada em literatura apontava um jovem escritor carioca como o novo fenômeno literário brasileiro. Publicado por uma das maiores editoras do país, a Companhia das Letras, Geovani Martins chegava ao mercado literário com o livro $O$ sol na cabeça, obra que reúne 13 contos ambientados nas favelas e periferias do Rio de Janeiro.

O autor, revelado na FLUP (Festa Literária das Periferias), nasceu em Bangu, já viveu na Rocinha e atualmente mora no Vidigal. Estudou até a oitava série, trabalhou de forma informal durante anos, até tomar a decisão de tentar viver de literatura.

Filho de cozinheira e de um jogador de bola amador, Martins encontrou apoio na mãe para seguir com sua decisão: "Falei: Mãe, eu quero fazer um livro, que vai possibilitar viver de livro - é o que eu sei e posso fazer. Não posso trabalhar fora para fazer isso, porque esse livro precisa ser muito melhor do que muita coisa. E para isso preciso trabalhar muito."2 A origem do jovem escritor colocou em dúvida a sua literatura, já que rapazes como Martins não costumam virar escritores.

Na 16ª Festa Literária Internacional de Paraty (FLIP), Geovani foi um dos convidados da programação oficial e esteve ao lado do escritor americano Colson

2 Entrevista do escritor para o jornalista Maurício Meireles no jornal Folha de São Paulo em 2 de março de 2018. Disponível em: <https://www1.folha.uol.com.br/ilustrada/2018/03/morador-defavela-no-rio-geovani-martins-desponta-como-escritor.shtml>. Acesso em: 8 ago. 2018. 
Withehead, na mesa Atravessar o sol’3, com mediação do professor de literatura brasileira Pedro Meira Monteiro. Ao abrir as perguntas para a plateia, uma pessoa não identificada perguntou para Martins se ele seria tão "incensado" como escritor se não tivesse vindo da favela. O autor, demonstrando irritação, disse: "Quem vai responder essa pergunta são os leitores. Tô fazendo o meu trabalho".

Além da sua origem, outros pontos chamaram atenção da crítica especializada e dos leitores. Um deles é a linguagem dos contos, que passa pela oralidade e vai até a considerada linguagem formal, o que marca, através desse recurso, as desigualdades sociais do país, como pontuou o jornalista e crítico literário do Jornal Suplemento Pernambuco, Miguel Conde (2018, online):

Na dicção que alterna a gíria do morro ("Rolézim") com o registro culto de reverberações literárias ("Travessia" faz pensar em Riobaldo, de Grande sertão: veredas, mas fala mesmo é de um traficante tentando desovar um defunto), a linguagem de Martins atravessa sem cerimônia as demarcações que reiteram, na língua, as divisões sociais do Brasil. Essa alternância não sugere, porém, algo como a tentativa de invenção de uma nova língua geral, um amálgama que prefigurasse uma superação futura dessa divisão, ou mesmo um encontro feliz no qual os dois registros pudessem se fecundar de maneira mútua, para pensar de novo em Guimarães Rosa. Em vez disso, conserva o sentido de transgressão e a inflexão de contraste, chamando atenção para as divisões que desrespeita.

Outro ponto que chama atenção nos contos de $O$ sol na cabeça é a representação dos personagens. Encontramos o jovem morador do morro, o pichador, o traficante, o maconheiro, sujeitos constantemente marginalizados pela literatura e pela sociedade. O olhar de Martins sobre esses sujeitos não é de crítica, de exotismo, de sensacionalismo midiático, de preconceito, é um olhar humanizado.

O autor de $O$ sol na cabeça é um jovem morador do morro que escreve sobre outros jovens e moradores do morro. Existe um olhar horizontal e não o olhar

\footnotetext{
3 A gravação da mesa Atravessar o sol pode ser vista no canal do YouTube da FLIP. Disponível em: <https://youtu.be/9hvFtomvVrI>.
} 
vertical. Um olhar de quem vivencia e é empático às desigualdades sociais do país. Como definiu Roberto Taddei (2018), "eis aí a pequena maravilha desse livro: enfraquecer o privilégio dos grupos dominantes na batalha pela representação do que é o humano na literatura brasileira".

O conto "Espiral" é um dos que representa essa humanização dos personagens e jovens moradores de favelas e periferias. O personagem principal começa a perceber que é o responsável por causar medo nas pessoas do asfalto na Zona Sul:

Começou muito cedo. Eu não entendia. Quando passei a voltar sozinho da escola, percebi esses movimentos. Primeiro com os moleques do colégio particular que ficava na esquina da rua da minha escola, eles tremiam quando meu bonde passava. Era estranho, até engraçado, porque meus amigos e eu, não metíamos medo em ninguém. Muito pelo contrário, vivíamos fugindo dos moleques maiores, mais fortes, mais corajosos e violentos. Andando pelas ruas da Gávea, com meu uniforme escolar, me sentia um desses moleques que me intimidavam na sala de aula. Principalmente quando passava na frente do colégio particular, ou quando uma velha segurava a bolsa e atravessava a rua pra não topar comigo. (MARTINS, 2018, p. 17)

[...] Tudo começou do jeito que eu mais detestava: quando eu, de tão distraído, me assustava com o susto da pessoa e, quando via, era eu o motivo, a ameaça. Prendi a respiração, o choro, me segurei, mais de uma vez, para não xingar a velha que visivelmente se incomodava de dividir comigo, e só comigo, o ponto de ônibus. (MARTINS, 2018, p. 18)

Nos seus contos, Geovani não descreve fisicamente os seus personagens. O leitor sabe apenas que são moradores das favelas do Rio de Janeiro. Em entrevista à TV PUC RIO, em junho de 2018, o escritor comentou sobre a questão racial na sua narrativa. O autor sempre se incomodou ao perceber que apenas os personagens não-brancos tinham a sua cor evidenciada em narrativas literárias. No seu projeto literário, ele optou por não usar características raciais e ainda assim todos os seus personagens são identificados como negros. 
Eu percebi a potência disso como provocação [...], qual o lugar da população negra na sociedade que a gente tem hoje? Por que determinadas histórias são ligadas diretamente à população negra? Isso já diz bastante coisa sobre como a gente enxerga e sobre como a gente tá vivendo também. (MARTINS, 2018, online)

A filósofa e ativista antirracismo Sueli Carneiro, em Racismo, sexismo e desigualdade no Brasil, diz que pobreza tem cor no Brasil. Quando se pensa em quem mora na comunidade pobre do morro logo se faz associação à população negra.

É de Joaquim Nabuco a compreensão de que a escravidão marcaria por longo tempo a sociedade brasileira porque não seria seguida de medidas sociais que beneficiassem política, econômica e socialmente os recém-libertados. $\mathrm{Na}$ base dessa contradição perdura uma questão essencial acerca dos direitos humanos: a prevalência da concepção de que certos humanos são mais ou menos humanos do que outros, o que, consequentemente, leva à naturalização da desigualdade de direitos. Se alguns estão consolidados no imaginário social como portadores de humanidade incompleta, torna-se natural que não participem igualitariamente do gozo pleno dos direitos humanos. (CARNEIRO, 2011, pos. 85)

O filósofo francês Michel Foucault aponta o racismo como uma técnica utilizada a favor do biopoder. Para Foucault (2019), a expressão máxima de soberania é a capacidade de ditar quem pode viver e quem deve morrer. Esse biopoder gerou a chamada biopolítica, a política da vida gerida pelo Estado. $\mathrm{O}$ conceito formulado por Foucault (2019) foi pensado nos contextos dos séculos XVII e XVIII levando em consideração o corpo como máquina capaz de ser adestrado e o corpo-espécie atravessado por processos biológicos.

[...] As disciplinas do corpo e as regulações da população constituem os dois polos em torno dos quais se desenvolveu a organização do poder sobre a vida. A instalação - durante a época clássica, dessa grande tecnologia de duas faces - anatômica e biológica, individualizante e especificante, voltada para os desempenhos do corpo e encarando os processos da vida caracteriza um poder cuja função mais elevada já não é mais matar, mas investir sobre a vida, de cima a baixo. (FOUCAULT, 2019, p. 150) 
A era do biopoder foi baseada na disciplina dos corpos e regulação da população, através de investimento e gerenciamento da vida, e administração dos corpos, de forma micro (por exemplo, sujeitando corpos nas escolas) e de forma macro (controle das populações, da natalidade, longevidade, habitação, saúde etc.).

O racismo age a favor dessa biopolítica ao permitir a dominação e desumanização de povos considerados diferentes devido a identidades sociais construídas historicamente desde o tempo da colonização e escravidão. Como disse Hannah Arendt (apud MBEMBE, 2018, p. 18), "a raça é, do ponto de vista político, não o começo da humanidade, mas o seu fim [...] não o nascimento natural do homem mas a sua morte antinatural".

Ao analisar a biopolítica de Foucault, o filósofo italiano Giorgio Agamben (2007) fala que a "vida nua do cidadão é o novo corpo biopolítico da humanidade". A chamada "vida nua" é aquela que surge nas condições do Estado de Exceção, quando suspendem-se os direitos de alguns a fim de restaurar a ordem. Agamben faz uma relação entre exceção e abandono:

A relação de exceção é uma relação de bando. Aquele que foi banido não é, na verdade, simplesmente posto fora da lei e indiferente a esta, mas é abandonado por ela, ou seja, exposto e colocado em risco no limiar em que vida e direito, externo e interno, se confundem. Dele não é literalmente possível dizer que esteja fora ou dentro do ordenamento (por isto, em sua origem, in bando, a bandono significam em italiano tanto 'à mercê de' quanto 'a seu talante, livremente', como na expressão correre a bandono, e bandito quer dizer tanto 'excluído, posto de lado' quanto 'aberto a todos, livre', como em mensa bandita e a redina bandita). É neste sentido que o paradoxo da soberania pode assumir a forma: 'não existe um fora da lei'. A relação originária da lei com a vida não é a aplicação, mas o Abandono. A potência insuperável do nómos, a sua originária 'força de lei', é que ele mantém a vida em seu bando abandonando-a. (AGAMBEN, 2007, p. 36) 
Quando há a suspensão dos direitos, quando o sujeito é banido, suspendese a sua condição humana. O professor doutor em direito do Estado, Pedro Serrano (2018) conceitua condição humana como também sendo "proteção jurídica e política que no ocidente pós-revoluções todo ser humano tem direito".

Vida nua é a vida matável e insacrificável do homo sacer, uma figura da lei romana que após cometer delito era banida da sociedade, podia ser assassinada por qualquer pessoa e não podia ser sacrificada em um ritual religioso. $\mathrm{O}$ termo "sacer" aqui não quer dizer "sagrado", mas sim algo "separado".

Aquilo que é capturado no bando soberano é uma vida humana matável e insacrificável: o homo sacer. [...]. Sacra, isto é, matável e insacrificável, é originariamente a vida no bando soberano, e a produção da vida nua é, neste sentido, o préstimo original da soberania. A sacralidade da vida, que se desejaria hoje fazer valer contra o poder soberano como um direito humano em todos os sentidos fundamental, exprime, ao contrário, em sua origem, justamente a sujeição da vida a um poder de morte, a sua irreparável exposição na relação de abandono. (AGAMBEN, 2007, p. 91)

Quem seria então o homo sacer contemporâneo? Qual é a vida nua matável e insacrificável nos dias hoje? A população pobre, periférica e negra. A escolha desse homo sacer é baseada no racismo. Como alerta Sueli Carneiro (2011), "é essa política de extermínio que cada vez mais se instala no Brasil, pelo Estado, com a conivência de grande parte da sociedade".

O personagem do conto "Espiral" resolveu transformar o medo, o susto, que causava nas pessoas em estudo sobre relações humanas. Teve cautela ao escolher a sua vítima. Mas um dia ela foi escolhida:

[...] era noite alta, um homem virou a esquina no mesmo momento que eu, trombamos. Ele levantou os braços, se rendendo ao assalto. Eu disse: "Fica tranquilo. E vai embora." Depois de muito tempo sentia mais uma vez aquele ódio primeiro, descontrolado, aquele que enche os olhos d'água. Há tempos já tinha me abstraído da humilhação e até mesmo da vingança. Encarava o desafio com o olhar cada vez mais distante, científico. Mas alguma coisa nos movimentos daquele homem - o levantar de braços, a expressão de terror fez reacender aquela chama do dia em que fui atrás da minha primeira 
vítima. Era ele. Só podia ser ele. Esperei um pouco e fui atrás, invisível. (MARTINS, 2018, p. 20)

O estudo realizado pelo personagem de Geovani Martins é audacioso. Ele escolheu testar seus limites e os limites da sua vítima. Observou, invisível, durante três meses, os hábitos, a família da sua cobaia, até que um dia foi visto e o medo e o terror começaram a fazer parte da vida do homem da zona Sul. O jovem do morro tremia diante das possibilidades do desfecho, mas seguiu em frente até que:

Ele entrou no prédio, cumprimentou o porteiro feito máquina, subiu. Apenas uma janela. Era o que se mostrava do apartamento no meu campo de visão. Fiquei mirando fixamente aquele ponto, sem me esconder dessa vez; se eu o visse, também ele me veria. Alguns minutos depois apareceu Mário, completamente transtornado, segurava uma pistola automática. Sorri para ele, percebendo naquele momento que, se quisesse continuar esse jogo, precisaria também de uma arma de fogo. (MARTINS, 2018, p. 21-22)

Foucault (2019) considerou a expressão máxima de soberania o poder e a capacidade de ditar quem pode viver e quem deve morrer. Quando um indivíduo se acha detentor dessa capacidade, ele se torna um soberano. E o outro indivíduo se torna o homo sacer, apontado por Agamben. "Na biopolítica moderna, soberano é aquele que decide sobre o valor ou sobre o desvalor da vida enquanto tal" (AGAMBEN, 2007, p. 149).

Quando o direito de matar sai da mão do Estado e passa para mão de um indivíduo, quando a morte é mais valorizada que a vida, a noção de biopoder trazida por Foucault (2019) não é mais suficiente. O filósofo camaronês Achille Mbembe, um dos pensadores mais importantes do pós-colonialismo, questiona:

Essa noção de biopoder é suficiente para contabilizar as formas contemporâneas em que o político, por meio da guerra, da resistência ou da luta contra o terror, faz do assassinato do inimigo seu objetivo primeiro e absoluto? A guerra, afinal, é tanto um meio de alcançar soberania como uma forma de exercer o direito de matar. Se considerarmos a política uma forma 
de guerra, devemos perguntar: que lugar é dado à vida, à morte e ao corpo humano (em especial o corpo ferido ou massacrado?) Como eles estão inscritos na ordem do poder? (MBEMBE, 2018, p. 6-7)

Mbembe (2018), em seu ensaio “Necropolítica: biopoder, soberania, estado de exceção, política da morte", questiona a biopolítica com base em modelos históricos e modernos do exercício da soberania, como a ocupação colonial, escravidão, o Estado Nazista e a ocupação colonial contemporânea da Palestina.

Enquanto a biopolítica trata sobre a política da vida gerida pelo Estado, Mbembe (2018) traz o conceito de necropolítica e fala de uma política da morte. O objetivo não é controlar o corpo, a vida, de determinados grupos, mas sim eliminar o corpo, a vida, de determinados grupos sociais. O objetivo principal é matar o sujeito apontado como inimigo.

No conto "Espiral", o personagem principal, o jovem do morro, tem o seu destino traçado por morar na favela do Rio de Janeiro, ele é pobre e negro, é o homo sacer contemporâneo, o inimigo político, aquele sujeito ao crime, a figura sobre a qual todos agem como soberanos. Esse Outro, apontado como um atentado contra vida dos homens de bem, uma ameaça mortal e perigo absoluto, cuja eliminação biofísica reforçaria o potencial de vida e segurança, essa delimitação é o que Mbembe (2018) chama de um dos muitos imaginários de soberania.

Esse imaginário de soberania retira a humanidade da população pobre e negra dos morros e já realiza o primeiro tipo de morte, a morte social, aquela que desumaniza, que tira proteção jurídica e política dessas pessoas, que as coloca como objeto, sujeitos com vidas descartáveis que podem ser tiradas por qualquer um.

O personagem do conto "Espiral" já tem a morte social anunciada, devido ao espaço geográfico em que vive, a favela. Essa morte social do povo negro é herança da escravidão. Mbembe (2018) diz que é impossível falar de terror 
moderno sem tratar da escravidão, considerada pelo filósofo como uma das primeiras manifestações da experimentação biopolítica.

[...] no contexto da plantation, a humanidade do escravo aparece como uma sombra personificada. De fato, a condição de escravo resulta de uma tripla perda: perda de um "lar", perda de direitos sobre seu corpo e perda de estatuto político. Essa tripla perda equivale a uma dominação absoluta, uma alienação de nascença e uma morte social (que é expulsão fora da humanidade). (MBEMBE, 2018, p. 27)

Um dos pontos que chamaram atenção para a literatura de Martins, como apresentado anteriormente, foi a humanização de seus personagens. O jovem do morro é consciente das diferenças. Ele sabe que o abismo que marca a fronteira entre o morro e o asfalto da Zona Sul é profundo. Mas de alguma maneira ele não esperava que fosse causar medo e susto na Zona Sul. Afinal, ele acreditava não ser perigo para ninguém. Ao contrário, existiam outros garotos mais fortes e temerosos do que ele. A sua humanidade, o seu medo, estava presente na favela, mas fora dela era inexistente. Geovani humaniza esse personagem e através do conto restitui a humanidade que é negada a diversos jovens negros.

Passado o turbilhão, fiquei com nojo de ter ido tão longe, lembrando da minha avó imaginando que aquela senhora também devia ter netos. Porém, esse estado de culpa durou pouco, logo lembrei que aquela mesma velha, que tremia de pavor antes mesmo que eu desse qualquer motivo, com certeza não imaginava que eu também tivera avó, mãe, família, amigos, essas coisas todas que fazem nossa liberdade valer muito mais do que qualquer bolsa, nacional ou importada. (MARTINS, 2018, p. 19)

A necropolítica, além de tratar da política da morte, abarca também a política de desaparecimento, ou seja, o sujeito que tem a sua morte social decretada é invisível para a sociedade e ele desaparece, vive à margem, separado, em constante estado de exceção. 
O filósofo chileno-brasileiro Vladimir Safatle, no artigo "Governar é desaparecer", no site da Revista Cult, comenta como o Estado brasileiro governa através dessa política de desaparecimento:

Com uma mão, ele massacra parte da população através de seu aparato policial, a encarcera em um espaço de não direito, permite a criação de zonas urbanas e rurais de anomia nas quais a violência e a morte são invisíveis, nas quais os corpos desaparecem sem deixar restos. Sobre esta parte da população, o Estado não tem apenas o direito de vida e morte, ele tem o direito de desaparecimento. Porque o eixo fundamental do processo de gestão é gerir a invisibilidade. Sobre esta violência, não haverá marcas, não haverá nomes, não haverá imagens, não haverá afeto nem identificação. (SAFATLE, 2017, online)

Se com uma mão o Estado brasileiro faz desaparecer, Safatle (2017) diz que com a outra ele promete segurança e proteção "a uma parcela amedrontada reunida em condomínios fechados". O Estado governa a invisibilidade e cria uma guerra civil com o inimigo interno declarado, o homo sacer contemporâneo.

A guerra civil, criada pelo Estado racista, a partir dessa cesura na sociedade, instaura o medo coletivo, aponta quem é o homo sacer contemporâneo, e faz com que a senhora do ponto de ônibus sinta medo do jovem do morro. As pessoas atravessem a rua ao ver um homem negro se aproximando sozinho na calçada. Faz com que Mário, o homem da Zona Sul do conto "Espiral”, tenha uma pistola automática e pense em usá-la contra o jovem da favela. Essa relação de inimizade é o que para Mbembe (2018) sustenta e normatiza o direito de matar, a necropolítica.

\section{REFERÊNCIAS}

AGAMBEN, Giorgio. Homo sacer: o poder soberano e a vida nua. Belo Horizonte: Ed. UFMG, 2007.

CARNEIRO, Sueli. Racismo, sexismo e desigualdade no Brasil. São Paulo: Selo Negro, 2011. E-book Kindle. 
CONDE, Miguel. Na travessia, ele inventou o próprio ritmo. Suplemento Pernambuco, 2018. Disponível em: $<$ http://www.suplementopernambuco.com.br/edi\%C3\%A7\%C3\%B5es-anteriores/72resenha/2071-na-travessia,-ele-inventou-o-pr\%C3\%B3prio-ritmo.html>. Acesso em: 4 ago. 2018.

FOUCAULT, Michel. História da sexualidade 1: A vontade de saber. Rio de Janeiro/ São Paulo: Paz e Terra, 2019.

JUSTIFICANDO. Pandora Lab - Estado de Exceção - Pedro Serrano. 2018. Disponível em: $<$ https://youtu.be/zUW2T0tZhtE>. Acesso em: 23 mai. 2018.

MARTINS, Geovani. O sol na cabeça. São Paulo: Cia das Letras, 2018.

MBEMBE, Achille. Necropolítica. São Paulo: Ed. n-1 edições, 2018.

SAFATLE, Vladimir. Governar é fazer desaparecer. Revista Cult, 2017. Disponível em: $<$ https://revistacult.uol.com.br/home/vladimir-safatle-governar-e-fazer-desaparecer/>. Acesso em: 23 mai. 2018.

TADDEI, Roberto. O Sol na Cabeça revela escritor capaz de ver o mundo com liberdade. Folha de São Paulo, 2018. Disponível em: <https://www1.folha.uol.com.br/ilustrada/2018/03/osol-na-cabeca-revela-escritor-capaz-de-ver-o-mundo-com-liberdade.shtml $>$. Acesso em: 8 ago. 2018.

TV PUC-RIO. A literatura vigorosa de Giovani Martins. (11m03s). 2018. Disponível em: <https://youtu.be/lDbpGHJy3jA>. Acesso em: 8 ago. 2018.

Nota do editor:

Artigo submetido para avaliação em: 18 de fevereiro de 2021.

Aprovado em sistema duplo cego em: 28 de julho de 2021. 